\title{
Adaptation of Collaborative Learning and Synectics Learning System for the Development of a Virtual Classroom for Educational College Creative Thinking at Roi Et Rajabhat University
}

\author{
Sakda Supap \\ Ph.D., Candidate in Industrial Education \\ Faculty of Industrial Education and Technology, \\ King Mongkut's Institute of Technology Ladkrabang (KMITL), Thailand

\section{Chantana Viriyavejakul} \\ Ph.D., Associate. Prof., \\ Faculty of Industrial Education and Technology, \\ King Mongkut's Institute of Technology Ladkrabang (KMITL), Thailand
}

Doi: $10.2478 / m j s s-2019-0055$

\section{Abstract}

This research is aimed at Developing a virtual classroom model using shared learning and syntactic learning To develop creativity of the College of Education students Roi Et Rajabhat University by researching and developing 3 steps of research: 1) Create a virtual classroom style using shared learning and Synthetics learning to develop creativity of the College of Education students Roi Et Rajabhat University. 2) Study the results of using the virtual classroom format by using joint learning and synthetics learning to develop the creativity of the College of Education students Roi Et Rajabhat University. 3) Presenting a virtual classroom using shared learning and Synthetics learning to develop the creativity of the College of Education students Roi Et Rajabhat University. The sample group consists of undergraduate students, Bachelor of Education Program Roi Et Rajabhat University Early Childhood Education Select by group sampling method (Cluster Sampling) The experimental group consisted of 30 students studying with a virtual classroom model using common learning and Synthetics learning to develop the creativity of the College of Education students Roi Et Rajabhat University with a control group of 32 people, normal students, statistics used to analyze data such as frequency, percentage, mean, standard deviation Nonindependent test statistics and independent test statistics and statistics for testing the relationship by value Pearson's correlation coefficient. Upon completion of the comparative study of achievement and study the satisfaction of students towards learning in a virtual classroom model Data analysis using mean, standard deviation T-test, the research found that; 1. Virtual classrooms using collaborative learning and synthetics to develop the creativity of the College of Education students Roi Et Rajabhat University is comprised of 6 components, namely 1) Learning system on virtual classroom 2) Communication and collaboration tools 3) Media content and learning resources 4) Student and instructor roles 5) Large group and sub-group 6) Learning Evaluation for the learning process together with 3 steps: 1) Process before class 2) Procedure during study consists of sub steps, which are 2.1) preparation for learners 2.2) classes consist of activities in large groups; stimulation and pulling ideas to create motivation, telling purpose, review previous knowledge, learn and present lessons, set the topic of the work by voting, point out learning methods and join activities in small groups (Activities in small groups set topics by voting, prepare and seek information, brainstorming, create works presenting work within a small group, comment vote to vote in large group showing comments, votes, votes and 3) evaluation 3 to 5 qualified persons assessed to certify the virtual classroom format by using mutual learning and learning of synthetics teaching to develop the creativity of higher education students in the field of education, education, science and related fields. There is a comment on the model developed by agreeing the most.

Keywords: virtual classroom, collaborative learning, synthetics, creativity 


\section{Introduction}

In today's society, expansion and rapid changes in many areas and new problems occur all the time. Therefore, there is a lot of competition in society making it necessary to use knowledge. Ability to be involved in living in society with equal knowledge, ability to develop and compete, learning just to be able to read, write and communicate is not enough in modern times. Quality development is important, especially the development of people with knowledge, wisdom and worldly knowledge. There is an opportunity for all Thais to be able to think, act, reason, be creative, and be able to learn throughout life. (Office of the Board National Economic and Social Development, 1999) Creativity is something that everyone has and can develop. Therefore, in order to be ready for social change, creativity, an essential element in promoting and developing the progress of the country should be advanced. In accordance with the principle that the more that people have originality or creativity, economic and social development will be more effective. However, from the study of the National Education Commission by exploring the problems in education in Thailand, it was found that most learners have less ability in the creative process. Therefore, creativity should be developed in learners. (Office of the National Education Commission, 1997) from the study found that important elements in promoting creativity include creating an environment, providing a favorable atmosphere, good parenting methods, proper teaching methods and techniques (Phanmanee, 2001) Teachers should be aware of various methods used in developing creativity

Therefore, the present form of education must be improved to make the most of learning, from traditional teaching styles to the form of more teaching and learning through electronic media. The technology used is teaching through a network, in various forms, such as learning through the internet in a virtual classroom (Virtual Classroom) to manage learning via the internet network Most often focus on Computer technology and communication networks are quite large because they are important structures. Often forgetting that there are still elements, another important aspect is teaching methods that will be incorporated into technology and will result in effective teaching and learning. (Thongdert, 2002) and (Ditsakun, 2000) Learning may be motivated by a variety of methods, but learning the good whole way should come from the true condition that is common in society. The way to learn is to learn from interaction. Bringing together learning activities on the internet helps to increase the efficiency and effectiveness of learning. This is another method that can make learning effective in Active Learning, by encouraging learners to work together. Mutual Learning (Collaborative Learning) to create new knowledge as well Mutual Learning is a successful teaching strategy in group style, where each learner has a different level of ability by using a variety of learning activities and increasing understanding of the content. Group members are not only responsible for learning, but also need to help transfer learning to friends in the group, which is a teaching concept that is consistent with change. Social institutions in modern times need to use the ability to build relationships of people with different abilities together in various matters ad can work together which is to change together for joint improvement. It can be seen that the use of the learning model of learning together through the network is very important to the students' learning because of the internet learning style, an important feature in helping to promote and support learners to interact with learning situations, allowing learners to contribute directly to the learners themselves. This can create motivation for students to learn well, starting to teach and to think, especially thinking creatively or motivating creativity and this is not difficult because everyone has their own creativity, each person only needing the opportunity to use existing potentials. By learning together learners will find ways to encourage creativity among themselves. There are many ways that Joyce and others (Gordon J.J. William. Synectics, 1986) and (Torrance, 1970)said that the teaching of Synectics is an interesting development of creative ideas and a theory of how to focus on people who are different, both in personality and ideas to jointly define problems in order to solve creative problems for the development of success in solving various problems efficiently. At present, undergraduate education and the surrounding society are very competitive and developing. There are people interested in developing creativity by applying various methods to experiment in teaching and learning, but still does not use the method of learning to teach synthetics with learning together in combination with a virtual classroom 
Recently, undergraduate education and the surrounding society are very competitive and rapidly developing, with groups developing creativity by applying various methods to experiment in teaching and learning. However, they still do not use the method of learning to teach synthetics by learning together in combination with a virtual classroom so that developing creative skills, working with others, learning through modern technology becomes necessary. Also needed is preparing to be able to adapt both physically and mentally to match the current organization that is constantly changing with efficiency and effectiveness.

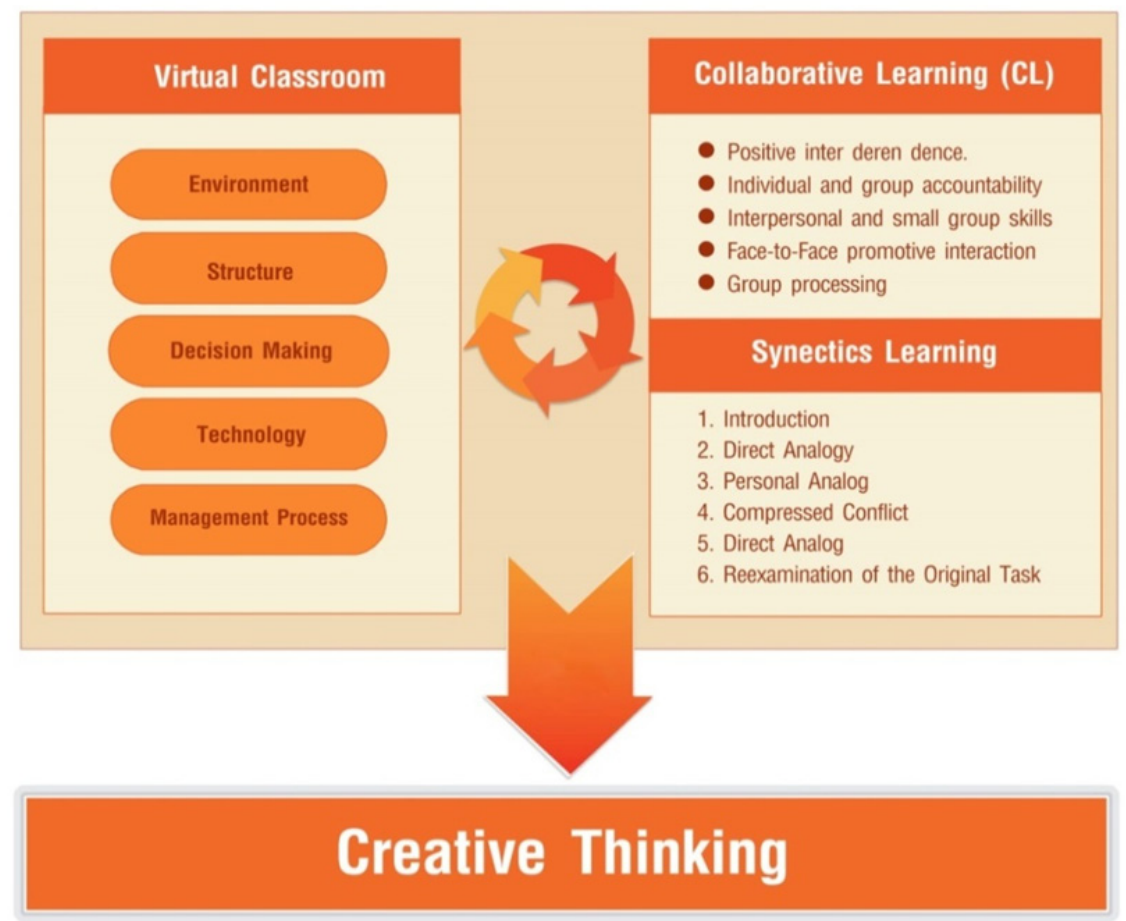

Figure 1. This is one example of a virtual classroom

\section{Research Purpose}

1. To study the condition of creating a model for the development of virtual classroom models by using collaborative learning and synthetics learning to develop the creativity of the College of Education students of Roi Et Rajabhat University

2. To improve the development of a virtual classroom model using shared learning and synthetics to develop the creativity of the College of Education students of Roi Et Rajabhat University

3. To study the results of using virtual classroom model development by using common learning and learning synthetics to develop the creativity of the College of Education students at Roi Et Rajabhat University

4. To present the results of the development of virtual classroom models using shared learning and learning synonyms to develop the creativity of the College of Education students at Roi Et Rajabhat University 


\section{Literature Review}

\subsection{Virtual Classroom}

A virtual classroom is an online learning environment that allows for live interaction between the tutor and the learners as they are participating in learning activities. In other words, the virtual classroom is a shared online space where the learners and the tutor work together simultaneously. Usually, these interactions take place through videoconferencing. The participants have tools to present learning content in different formats, as well as to implement collaborative and individual activities. In this type of interaction, the teacher has the particularly important role of the moderator who guides the learning process and supports group activities and discussions. (Veronica, 2017).

\subsection{Collaborative Learning}

Collaborative learning is a successful strategy conducive to group learning. Students possessing different ability and performance would expose themselves to diverse learning activities added with contents to provide better understanding. Members in the group not only are responsible for their own learning but also contribute to learning or knowledge transfer to other group members. This learning concept is in line with changes of social institutions at present that requires ability to establish relationship among students with different abilities or heterogeneous group through such activities as working together, changing together, developing together, etc. (Thongdilerd, 2002)

\subsection{Synectics Learning}

The name of the Synectics model comes from the Greek word synecticos meaning "understanding together that which is apparently different" The father of the Synectics model, Gordon according to whom it is an operational theory, bases the entire theory on a belief that the creative process can be taught using analogous and metaphorical thinking Gordon identified strategies that creative people use unconsciously and developed these strategies into teachable forms (Davis \& Rimm, 1998)

\subsection{Creativity Learning}

Creativity is an attribute that everyone can possess and nurture. To cope with such societal changes, it is indispensable to develop creative capacity or creative thinking which is a very important element to promote and develop the prosperity of the country in accordance with the principle that the more initiative or creative the human resource, the more effective and favorable the economic and social development will become. Nevertheless, according to the study of educational problem in Thailand conducted by the Office of the (National Education Commission, 2002) most students were found to be lower in the ability of creative thinking process; therefore, according to Office of the Prime Minister

\section{Methodology}

Research on the development of a virtual classroom model using shared learning and synthetics to develop the creativity of the College of Education students at Roi Et Rajabhat, University Of the College of Education students Roi Et Rajabhat University as follows;

1. Model for developing a virtual classroom model by using joint learning and synthetics to develop the creativity of the College of Education students at Roi Et Rajabhat University. The researcher used the method of (Phuwan, 2000) consisting of;

- Elements of the model development model of a virtual classroom using shared learning and synthetics to develop the creativity of the College of Education students at Roi Et Rajabhat University

- Learning activity steps of the model development of virtual classroom using shared 
learning and synthetics to develop the creativity of the College of Education students at

Roi Et Rajabhat University

2. Content used in the experiment

This study uses the content of the ECE2703 (Learning Materials for Early Childhood) media for early childhood education, Early Childhood Education Graduate School of Education Roi Et Rajabhat University

3. Population of research

Population is the college students of education, Early Childhood Education Bachelor of Education Program College of Education Roi Et Rajabhat University

4. Sample of research

The sample group was made up of students who were studying at the bachelor's level, year 2, semester beginning of the academic year 2015, early childhood education, Bachelor of Education Program College of Education Roi Et Rajabhat University which was obtained by purposive selection method, consisting of 1 classroom, a total of 50 people, divided into 2 groups: experimental group (virtual classroom model) and control group (Normal classroom) 25 people per group, with the researcher using the method of (Bun Riang, 2000).

5. Study variables

- Independent variable:

Learning with a virtual classroom model using shared learning and Synthetics learning.

- Dependent variables include creativity

Table 1. Average and standard deviation Expert opinion on the model of virtual classroom using shared learning and synthetics to develop the creativity of the College of Education students at Roi Et Rajabhat University

\begin{tabular}{l|c|c|c}
\hline Side information & M & S.D. & meaning \\
\hline 1. Meets the needs of system users & 4.63 & .17 & excellent \\
\hline 2. Work according to the function of the system & 4.59 & .08 & excellent \\
\hline 3. Ease of use of the system & 3.80 & .14 & good \\
\hline 4. System performance & 4.00 & .37 & good \\
\hline 5. Data security in the system & 4.28 & .27 & good \\
\hline All aspects & 4.46 & .07 & good \\
\hline
\end{tabular}

From Table 1, experts can see that the efficiency of the virtual classroom model by using learning.

Together and learning synonyms to develop the creativity of the College of Education students at Roi Et Rajabhat University, the overall picture is good. When considering each aspect, it was found that the demand for working systems according to the system functions was at a very good level. For the ease of using the system, performance of the system and the security of information were all at a good level, which is consistent with the method of (Boonlue, 2007) in conducting research on the development of teaching styles using problem-based virtual classrooms in higher education where the results showed that the work of the virtual classroom model is very good.

Finding the model performance of a virtual classroom using common learning and learning synthetics for the development of creative thinking of college students at Roi Et Rajabhat University After obtaining the model that has been evaluated appropriately, a lesson was created with the website by analyzing the course description ECE2703 (Learning Materials for Early Childhood) Learning media for early childhood, and then determine the content to create the website. Next was to determine the behavioral objectives of each subject and create a website according to the format developed which was brought to 3 educational technology experts to assess the content, validity and design techniques as well as presenting the website media. Once finished and a new website created, efficiency was found according to the criteria $80 / 80$ by experimenting with the sample which was divided into 3 times, ie the time 1 Experiment with 3 students for initial quality examination, the understanding of the lesson content, Meaning, Presentation method and steps to perform various activities by observing the interview and applying the information that were revised for the 2nd time, experimenting with 9 students to find the trend of the website's performance and 
examined for defects in various areas, which was then used to improve the 3rd time, and conducted experiments with 30 students to find the effectiveness of the virtual classroom model by using joint learning and Synectics learning To develop the creativity of the College of Education students of Roi Et Rajabhat University using exercises and achievement tests created after students had studied the theoretical lesson material in each topic, completed collecting points to find efficiency (E1) and when students had studied all the contents of every topic, students took the test to collect points for efficiency (E2) showing efficiency E1 / E2 equal to 85.87 / 84.13, which corresponds to the method of (Phrom Wong, 1993).

Procedures for studying the effects of classroom management in a virtual classroom model using joint learning and Synectics learning to develop the creativity of the College of Education students at Roi Et Rajabhat University

6. Population and sample group

- Pachakorn group includes undergraduate students Bachelor of Education Program Early Childhood Education of Roi Et Rajabhat University Enrolled in ECE2703 (Learning Materials for Early Childhood) learning media for early childhood, 1st semester, academic year 2015, total of 5 classrooms, a total of 150 students

- The sample population was undergraduate students, Bachelor of Education Program Early Childhood Education of Roi Et Rajabhat University who enrolled in ECE2703 (Learning Materials for Early Childhood) learning media for early childhood, 1st semester, academic year 2015, 2 classrooms, a total of 62 students, selected by sampling group method (Cluster Sampling) Students were from 2 rooms to 5 rooms, each classroom having students who were able to mix with both medium and soft students in the same room. From there, they were randomly assigned to 1 room as an experimental group Another room was the control group, (sample random sampling) The experimental group was a study room with a virtual classroom model using collaborative learning and synthetics. To develop the creativity of the College of Education students at Roi Et Rajabhat University, 30 people and the control group was a normal study room. There were 32 students.

- Tools used for data collection:

- Learning achievement test; The researcher created a multiple choice test with 5 options, 100 items, which were sent to the content validity experts. After that, the test was used to determine the quality. The accuracy was .87 .

- Student satisfaction questionnaire for learning by simulating a virtual classroom using shared learning and synthetics to develop the creativity of the College of Education students at Roi Et Rajabhat University. There were 4 aspects: group characteristics and group processes for learning exchange; activities, technology, learning support and benefits The researcher used the satisfaction questionnaire to test for quality by calculating Cronbach's alpha coefficient ( $\alpha$ - Coefficient) equal to .82 .

7. Data collection

- Introduce teaching methods to students in the experimental group and control groups along with making a pre-test.

- The students in the experimental group started studying with a virtual classroom model using shared learning and Synectics to develop the creativity of the College of Education students at Roi Et Rajabhat University According to the learning management plan, there are steps as follows; Preparation stage To make an appointment at the same time, The process of teaching and learning activities consisting of learning goals Research Study exchange Storage Utilization which takes 4 lessons, 50 minutes per lesson and having students complete the exercises at the end of each chapter.

- Students in normal control classes have instructors as lecturers in the classroom according to the normal management plan and complete the exercises at the end of each chapter.

- Post-test to measure achievement using the same set of examinations as before in both groups. 
- Ask the satisfaction of students studying with simulations of a virtual classroom using collaborative learning and synthetics. to develop the creativity of the College of Education students at Roi Et Rajabhat University.

8. Data Analysis

- Compare scores before class and after class with virtual classroom models using collaborative learning and Synectics learning to develop the creativity of the College of Education students at Roi Et Rajabhat University By testing the sample values that are independent of each other (t-test Dependent Samples).

- Compare scores before class and after study with virtual classroom models using collaborative learning and Synectics to develop the creativity of the College of Education students at Roi Et Rajabhat University Normal group by t-test Independent Samples.

- Analyze the satisfaction of students towards learning by simulating a virtual classroom using shared learning and Synectics to develop the creativity of the College of Education students at Roi Et Rajabhat University by finding the mean and standard deviation.

\section{Results}

Based on research, creating a virtual classroom model using shared learning and Synectics to develop the creativity of the College of Education students at Roi Et Rajabhat University and can summarize the results as follows

5.1 Results of comparison of scores before and after studying with simulations of virtual classrooms using shared learning and synthetics to develop the creativity of the College of Education students at Roi Et Rajabhat University

Table 2. Comparison of scores before and after class.

\begin{tabular}{l|c|c|c|c}
\hline score & N & M & S.D. & t \\
\hline Before class & 30 & 25.47 & 4.00 & \multirow{2}{*}{$72.97^{* *}$} \\
\hline After class & 30 & 87.57 & 2.32 & \\
** statistical significance at the level of .01
\end{tabular}

From Table 2, it was found that all students had an identical average score before studying with a virtual classroom model using common learning and synthetics to develop the creativity of the College of Education students Roi Et Rajabhat University. After studying, however, 25.47 was the control and the other group average after school score is 87.57. When comparing scores before and after study It was found that the average score after the study was higher than before learning with the statistical significance at .01 level, which is consistent with the research of (Kasem Rasmus, 2003) who stated that the results of research on web-based cooperative learning towards creative development of upper secondary school students study of the art education program found that the average score after studying was higher than before studying.

5.2 The results of the comparison of learning achievement of students studying with a virtual classroom model by using joint learning and synthetics learning to develop the creativity of the College of Education students at Roi Et Rajabhat University with students who study normally.

Table 3. The results of the comparison of learning achievement of students studying with a virtual classroom model by using joint learning and Synectics learning to develop the creativity of the College of Education students at Roi Et Rajabhat University with students who study normally.

\begin{tabular}{l|c|c|c|c}
\hline Score & $\mathbf{N}$ & $\mathbf{M}$ & S.D. & t \\
\hline Control group & 32 & 80.33 & 3.43 & \multirow{2}{*}{$5.60^{* *}$} \\
\hline Experimental group & 30 & 84.57 & 2.32 & \\
\hline
\end{tabular}

** statistical significance at the level of .01 
From Table 3, it was found that the average score of students studying with a virtual classroom model using shared learning and synthetics learning to develop the creativity of the College of Education students at Roi Et Rajabhat University equals 87.57 and the average score of students who study normal style is 80.33 When comparing learning achievement It was found that the learning achievement of students who learned by simulating a virtual classroom by using collaborative learning and Synectics learning To develop the creativity of the College of Education students Roi Et Rajabhat University Higher than students who study normal style With statistical significance at the level of .01, which is consistent with the research of (Supang, 2004) who stated that the results of research on the development of a cooperative learning model in collaboration Project management in a virtual classroom For undergraduate students, Faculty of Education, Chulalongkorn University Found that the test scores of students studying with virtual classroom have higher learning results than students who study normal classroom.

Table 4. Average and standard deviations of the level of satisfaction of students studying with a virtual classroom model by using joint learning and Synectics learning to develop the creativity of the College of Education students at Roi Et Rajabhat University.

\begin{tabular}{l|c|c|c}
\hline Information & M & S.D. & Meaning \\
\hline 1. Group traits and group processes & 4.68 & .26 & most \\
\hline 2. Exchange activities & 4.60 & .32 & most \\
\hline 3. Technology support & 4.51 & .33 & most \\
\hline 4. most benefit & 4.55 & .22 & most \\
\hline All aspects & 4.58 & .21 & most \\
\hline
\end{tabular}

From Table 4, it was found that students were satisfied with the study by simulating a virtual classroom using shared learning and synthetics to develop the creativity of the College of Education students at Roi Et Rajabhat University. The overall picture is at the highest level. When considering each aspect it was found that the group characteristics and group processes showed students are more satisfied than with other aspects, which is consistent with the research of (Supap, Viriyavejakul, \& Brahmawong, 2016) in the research on Developing a Virtual Classroom Model of Collaborative Learning and Learning to Cultivate Creative Capacity or Creative Thinking Among Students of Faculty of Education. Students' creativity has the highest level of satisfaction with learning with a virtual classroom.

\section{Discussion}

It can be summarized as a result of the development of a virtual classroom model using shared learning and Synectics learning to develop the creativity of the College of Education students at Roi Et Rajabhat University has 4 episodes as follows

6.1 Episode 1 The results of the survey and analysis of opinions on research and development of virtual classroom models using shared learning and synthetics to develop the creativity of the College of Education students at Roi Et Rajabhat University.

The course content management system is made up of communication system, teaching and learning tracking systems, the evaluation system and mutual learning. The researcher used the system method (Kritthan Wattanaarong, 2011). In the field of teaching and learning in Syncetics and creativity by respondents as students in the first semester of academic year 2015, there are 2 classrooms and a total of 62 students. The sample group is selected by cluster random sampling method (Cluster Sampling). There are 2 rooms made from 5 rooms, each classroom having students who are able to mix with both medium and soft students in the same room. From there, 1 room is randomly assigned as an experimental group. Another room is a control group. By sample random sampling, the experimental group is a study room with a virtual classroom model using collaborative learning and synthetics to develop the creativity of the College of Education students 
at Roi Et Rajabhat University, with 30 people and the control group is a normal study room with 32 students. (Supap, Viriyavejakul, \& Brahmawong, 2016)

Summary of the overall survey results of the first semester of the academic year 2015, 2 classrooms, a total of 62 students. The sample group was selected by cluster random sampling method (Cluster Sampling) for 2 rooms from 5 rooms, moderate and soft in the same room. From those rooms, randomly assigned was 1 room as an experimental group Another room is a control group. ( sample random sampling) The experimental group is a study room with a virtual classroom model using collaborative learning and synthetics to develop the creativity of the College of Education students at Roi Et Rajabhat University, 30 people and the control group is a normal study room of 32 students with a level of satisfaction and needs of the general condition of the instructor in the management system of users and course management. This was for the course content management system Communication system. In the course of tracking the course (Course Tracking) in the measurement system, evaluation (Assessment), questionnaire about learning together In the field of teaching and learning in synthetics and creativity helped to find the average picture of all aspects in a very high level, which is consistent with the research of (Khem Chatpong Phan, 2011), who said that each student has a student who has a mixed ability, with both moderate and soft students.

6.2 Episode 2 The results of the development of a virtual classroom model using shared learning and Synectics to develop the creativity of the College of Education students at Roi Et Rajabhat University. The learning model prototype consists of 6 elements and 3 big steps and sub-steps as follows.

1. There are 6 elements: The researcher usedthe method (Surasak, 2017). 1) Learning system on virtual classroom 2) Communication and collaboration tools 3) Media content and learning resources the content is related to SYNECTICS, using metaphors or metaphors (METAPHORIC ACTIVITY) in contradictory or unfamiliar things which makes the learner create new ideas, be able to create new works or be themselves which are beneficial to oneself and society or making strange problems familiar. The metaphor for the four characteristics in the comparison is the metaphor based on itself (PERSONAL ANALOGY) Direct metaphors (DIRECT ANALOGY) Based on metaphors (SYMBOLIC ANALOGY) and Figurative based on fantasy (FANTASY ANALOGY) 4) Roles of learners and instructors 5) Major group activities and subgroups 6) Evaluation

2. The learning process together with 3 big steps is

- The researcher used the method of (Thana $\mathrm{Na}$, 2002).Proceedings before class (Conducted in normal classrooms) divided into steps as follows: Orientation Doing creative measurement form before class, Explore information and skills of learners, Determine the role of learners and instructors, Establish agreement on joint activities, Determine the terms of measurement and evaluation and Training on the use of related computer programs

- Procedure during the study consists of the following steps, the researcher used the method of (Thana Na, 2002).

Preparing learners 1) Entering the virtual classroom (by LOGIN and enter PASSWORD password) 2) Introduce yourself to others Introduce yourself to others. Open your mind, talk, share opinions. In order to become familiar with each other to collaborate on virtual classroom activities

Classes (shared learning within a large group on a virtual classroom), arranged in the following order: 1) Stimulate and draw ideas for motivation 2) Objectives 3) Review the previous knowledge 4) Learn and present lessons the instructors use the method of lecturing to support the case by using various media. And practicing synthetics activities in 4 different forms in the presentation of the content 5) Set the topic of the work by voting (Let everyone participate in the vote By using POLLING tools in the virtual classroom) 6) Identify learning guidelines 7) Participate in small group activities (Learning together within every subgroup by allowing the learners to choose their own 
group, each group of 4-6 people. The group of learners assigns sub-topics to create works in small groups and the scope of the study in that matter may use the voting method by the instructor as a guide, or give advice, control and facilitate learning for students. The students in the sub-group use the method of brainstorming, comment and participate in voting to select sub-topics that must be done within that particular group 8) presenting work to large groups

- Evaluation steps are as follows: 1) evaluate the work and presentation (Assessment on virtual classroom) 2) Create creative measurement after study (Assessed on a regular classroom) 3) satisfaction assessment questionnaire (Assessed on a regular classroom) 4) make a self-assessment questionnaire for friends and teachers (assessed on a regular classroom)

3. Results of the quality assessment of the virtual classroom model created from experts in various fields associated $A$ total of 15 people have the following results;

In all aspects which consist of elements Learning process, the evaluation process has an average value of 4.62 , standard deviation of 0.23 . Compared to the set criteria, experts have opinions on the virtual classroom format at the most appropriate level, which is consistent with the research of (Suphathida, 2003) who said that the evaluation of performance to get the software that works as needed, can be used.

\section{Conclusion}

Results of the analysis of the relationship between the results of the creative score of experts; In the overall picture, it was found that the relationship between the 3 experts of the creative score test results of language, picture and pre-written language (POST-TEST) of the experimental group, there is a positive correlation with statistical significance at .05 level, which is consistent with the research of (Thaweewat, 2004), who said that the creative score before and after school of the experimental group were positively correlated with statistical significance at .05 level.

Analytical results of creative scores in languages, images and written language; In the overall picture, it was found that the values of creative thinking in all 4 areas were thinking, fluency, flexible thinking, initiative and thoughtful thinking, found that the total score of creativity in all 4 aspects and the creative score included language, picture and written language of the experimental group The scores of the 3 creative ideas of the written language of the experimental group and the total score of creative thinking in 4 areas and creative score including language, picture and writing language of the experimental group after studying were higher than before learning with statistical significance at .05 level, which is consistent with the research of (Dilok, 2534), who said that the total score of 3 creative ideas of the written language of the experimental group and the total score of creative thinking in 4 areas and creative score including language, picture and writing language of the experimental group after studying significantly higher than before studying.

Results from the evaluation of satisfaction in various aspects of students; Divided into 3 aspects, namely the results from the evaluation of media satisfaction Results from teaching and learning management and results from the evaluation of mutual learning, satisfaction results from content satisfaction assessments SYNECTICS and creativity in all 3 aspects. Students are satisfied with the overall picture of the media in the classroom format. The average value is 4.57 . The standard deviation 0.56 is at a high level, the best Self-assessment results: Friends within the group Including media and content Instructors and teaching methods; The Sample provided an overview of the media content of the instructor that is appropriate in many areas, consistency, variety, and comprehensive, clear, easy to understand, with links to ideas that can create creative processes as well. For self-assessment Friends and instructors assessed themselves and friends with most giving points in participation and learning together within the group. In the self-assessment section they will give the average self score at the highest level and let colleagues within the average score group be at the highest level as well. Which is consistent with the research of (Thawatchai, 2003) stated that learning materials are appropriate Have variety Content is consistent Clear and easy to understand, which is consistent with the research (SUPAP, VIRIYAVEJAKUL, \& BRAHMAWONG, 2017) and (Wachanida, 2010). Students are free to offer opinions and research to do activities to 
exchange knowledge where is help to share information with each other and can contact the instructor at any time.

Episode 4 The results of the presentation of the virtual classroom model: The researcher favors adopting the learning style. Supporting documents Together with a certificate of learning style developed for 5 experts to consider, certify and provide additional suggestions in the relevant aspects of the pattern, Developing a virtual classroom model using shared learning and syntactic learning to develop the creativity of the College of Education students at Roi Et Rajabhat University. This consists of concepts, basic theories of learning, the purpose of learning, and the learning system on the virtual classroom. In terms of communication and working tools, content, media, learning resources, learning time, roles of learners and organizing learning activities, the measurement and evaluation of the practical implementation steps was expressed by the experts whose opinions of the format, content, media, learning resources, learning time, roles of learners and organizing learning activities proved to be good. In the measurement and evaluation of the practical implementation steps, the experts have commented that the virtual classroom model using collaborative learning and synthetics teaching to develop the creativity of the students of the College of Education at Roi Et Rajabhat University were very good overall. The average of all images has a mean value of 4.69 , standard deviation of 0.10 and can be used in the most level The average of all images has a mean value of 4.69, standard deviation of 0.10 and can be used in the most level.

The average of all images has a mean value of 4.69 , standard deviation of 0.10 and can be used in the most level, which is consistent with the research of (Boonrueang Niamhom, 1997) that says learning on a virtual classroom, communication and collaboration tools for content, media, learning resources, learning time, role of learners and in organizing learning activities, measurement and evaluation of the practical implementation steps, being consistent with Johnson's research, D. W., Johnson (1990) Has studied the working group of students using the Syncetics model, found that it is a model that develops students to be creative by using brain-raising techniques developed by William JJ Gordon and George Prince in the 1960s (Gordon, 1961) made many students achieve higher grades.

\section{Acknowledgements}

I would like to express my sincere thanks to my thesis advisor, Associate Professor Dr. Chantana Viriyavejakul for her invaluable help and constant encouragement throughout the course of this research. I am most grateful for her teaching and advice, not only the research methodologies but also many other methodologies in life. I would not have achieved this far and this thesis would not have been completed without all the support that I have always received from her. In addition, I am grateful for the: Professor. Dr. Chaiyong Brahmawong, Ministry of Higher Education, Science, Research and Innovation, Roi Et Rajabhat University, and others person for suggestions and all their help.Finally, I most gratefully acknowledge my parents and my family for all their support throughout the period of this research.

\section{References}

Aree Phanmanee. Development of creativity to excellence, Thanachai Printing Co., Ltd., 2001.

Bunrangkhajonsilp. 2000. Research methods in education. Type 5. Bangkok: PN Printing

Boonrueang Niamhom. (1997). Development of the internet teaching system at the tertiary level. Degree Master of Education Department of Audio-Visual Studies Chulalongkorn University. (Copy)

Chaiyong Promwong. 1993. Synthesis of educational systems. Information technology System Education: Nonthaburi: Sukhothai Thammathirat Open University.

Davis, G. A., \& Rimm, S. B. (1998). Education of the Gifted and Talented (4th Edition). Boston, MA: Allyn \& Bacon

Dilok Dilkanon. 2534. Practice of thinking skills for promoting creativity. Degree Master's thesis, curriculum research and development College Srinakarinwirot University.

Gordon J.J. William. Synectics: The Development of Creative Capacity, Collier-Macmillan Ltd, 1968. 
Johnson, D. W., Johnson, R. T., and Holubec , E. J. 1990. Circles of Learning: Cooperation in the classroom. Edina, MN: Interaction Book Company.

Kritthan Wattanaarong. (2011). Technological innovation and educational technology. 2nd edition, Bangkok: University King Mongkut's University of Technology North Bangkok

Khem Chatphong Phan. (2011). Development of teaching and learning via internet, social networks Re: Creating formulas and calculating functions Course for using the schedule program. Special Problems (Computer Technology). Bangkok: Graduate School, University King Mongkut's University of Technology North Bangkok.

Kasemsarit Wisitkunkasem. 2003. The effect of cooperative learning on the web on the development of ideas Creation of high school students Study of the art education program. Master's thesis, Department of Primary Education Faculty of Education, Chulalongkorn University University.

Office of the National Education Commission. Educational reform guidelines Tertiary Level National Education Act BE 2542, Teachers Council of Thailand, Lat Phrao, 2002.

Office of the National Education Commission. Summary of the 8th National Educational Development Plan (1997-2001), The Teachers Council of Thailand, Lat Phrao, 1997.

Pichai Thongdert. "E-Learning Technology or Method", Telecom Journal or / Telecom Journal, Issue 20, 5-11 August 2002. Page 58-59.

Supap, S.,Viriyavejakul, C., \& Brahmawong, C. (2016). Develop Virtual Classroom Model of Collaborative Learning andSynectics Learning to Cultivate Creative Capacity or Creative Thinking Among Students of Facultyof Education. Asian International Journal of Social Sciences, 16(2), 110 - 123.

Supap, S., Viriyavejakul, C., \& Brahmawong, C. (2017). Development of Virtual Classroom Model of Collaborative Learning and Synectics Learning to Cultivate Creative

Capacity for Students of Faculty of Education Roi Et Rajabhat University. Proceedings of the 9th international conference on humanities and social, 77-87. http://fs.libarts.psu.ac.th/research/conference/proceedings9/Proceedings-9.pdf

Supang Thai Somboon Suk. 2004. Development of a cooperative learning model in the subject group Project management in a virtual classroom For undergraduate students Faculty of Education, Chulalongkorn University. Master's thesis Department of Audio-Visual Studies Chulalongkorn University.

Supin Ditsakun. Mutual Learning, Journal of Educational Review, Issue 15, May-August 2000. Page 1-8.

Surasak Phahe. (25560). Educational technology paradigm in the digital age. Bangkok: Suviriyasasan.

Torrance, E.P. Creativity and Infinity. Journal of Research and Development in Education, No. 3, November 1970 , pp. 22-29.

Thawatchai Adeepathit. (2003). "E-Learning with Virtual Classroom". Journal of Academic Resources. 2 (May August), $62-65$

Thawiwat Wattanakulcharoenkit. 2004. Development of a measurement model based on actual results from Learning electronics that use learning methods according to situations that affect awareness The ability of self-learners in educational institutions Higher education. Thesis Ph.D., Education and Communication Technology, Chulalongkorn University.

Than Na Khaemmanee. (2002). Science of teaching knowledge for organizing the learning process Efficiency. Bangkok: Chulalongkorn University Publishing House.

Thongdeelerd, P. (2002). e-Learning: Technology or Methodology. Telecom Journal, 21, 58-59.

Torrance, E.P. (1970). Creativity and Infinity. Journal of Research and Development in Education, 3, 22-29.

Veronica R.(2018). Online communication in learning and teaching.New York.NY:Palgrave Macmillan.

Wanida Phrachai. (2010). CIPPA MODEL teaching about surface area and volume towards Learning achievement and assertive behavior of students with different learning abilities.Education: Master's degree thesis (Secondary education). Bangkok: Graduate School Sri University Nakharinwirot Prasarnmit. Photocopying.

Yuen Phu Wan. 2000. Teaching and Learning Reform in Thailand. Microcomputer. June. 